\title{
Sedimentation of water dispersed systems of acrylate copolymers in xylene
}

\author{
Edwin Makarewicz, Anna Zalewska \\ University of Technology and Life Sciences, Faculty of Chemical Technology and Engineering, ul. Seminaryjna 3, \\ 85-326 Bydgoszcz, Poland, e-mail: makar@utp.edu.pl, aniazal@utp.edu.pl
}

\begin{abstract}
Methyl methacrylate - butyl acrylate - methacrylic acid copolymer and butyl methacrylate - methacrylic acid amide copolymer of a different segmental structure were stabilised with non-ionic and anionic surfactants. Gel chromatography, viscosimetry, tensiometry, conductometry and sedimentation methods were applied to define the properties of the synthesized copolymers, surfactants in water solutions and water dispersions. The types and the properties of the phases being in a state of sedimentation balance were also determined. The obtained experimental data were interpreted and justified by using the copolymer and surfactants properties. The existing correlations were pointed out. The obtained results show that the stability of a disperse system considerably depends on the structure of the copolymer. The MMA/BA/MAA copolymer has monomeric units of elastic butyl acrylate. Segments containing these monomeric units adsorb surfactants much better and form more stable water disperse systems. However, the MBA/AMAA copolymer with the polarity of amide group of methacrylamide makes disperse systems less stable.
\end{abstract}

Keywords: polymer, water colloid dispersions, sedimentations, stability.

\section{INTRODUCTION}

Water-soluble paints are a modern type of painting materials. They are stable dispersions of polymers in aqueous environment. Surfactants, high-molecular compounds and protective colloids are used to obtain their stabilisation. The surfactants are adsorbed on the surfaces of polymer particles up to the moment of reaching a balance. The stability of any disperse system consists in unchanged properties in its whole volume range in a long period of time ${ }^{1-5}$.

Disperse systems are characterised by a strong development of phase boundary of polymer particles and their dispersing environment. This phenomenon is connected with the existence of a considerable Gibbs free energy, the reduction of which results in spontaneous coalescence and coagulation of particles. It means that disperse systems are basically thermodynamically unbalanced, where aggregation of the dispersed phase particles takes place and their further sedimentation results in forming a sediment or foam ${ }^{6-11}$.

The process of dispersing is connected with an increase of Gibbs free energy and runs easier with lower surface tension. The introduced surfactants make adsorptive layers which protect particles against coalescence. The general stabilizing capacity of the surfactants depends on the particle geometry and size, the thickness of the adsorptive layer, the concentration of the surfactant on the surface of a particle. The coalescence of the dispersed particles is generally a result of the desorption of the surfactant. The stabilizing activity of the surfactant consists not only in a decrease in surface tension on the interface but also in the formation of a structuralmechanical barrier providing the stability for the dispersed particles. The particles settle under the effect of gravity force. On the other hand, Brownian movement occurs to distribute the particles evenly in their total volume. Finally, after an infinitely long time, all the dispersed particles cannot settle totally. Some degree of sediment equilibrium is reached. It consists in establishing different numbers of particles in each horizontal layer of the system from the top to the bottom of the vessel in which the dispersion takes place. In macroscopic systems in which sedimentation of large particles prevails with an interaction between these particles (the network bound is created by using ticsotropic additions) the phenomenon of diffusion is observed in a limited range. On this type of the dispersed systems, the settlement of sediment balance is most possible after a relatively long time ${ }^{\mathbf{1 2}-15}$.

The diversity of the phenomena observable during the process of destabilising the disperse systems is difficult to describe by using one universal theory. The sedimentation observations and the studies are one of the methods of an experimental description of the phenomena carried out in disperse systems ${ }^{16} \mathbf{- 2 0}$.

The aim of this study was to determine the factors having an effect on the sedimentation stability of water-based dispersions of copolymers in xylene solution: methyl methacrylate - butyl acrylate - methacrylic acid (MMA/BA/MAA) and butyl methacrylate - methacrylic acid amide (MBA/ AMAA) of a different segmental structure, i.e. of different molar fractions of monomers in the copolymer. Basing on the experimental data, the relations between the quantities describing sedimentation were formulated and their theoretical interpretation was given. The tested copolymers were used to obtain protective films of the best physico - chemical properties.

\section{EXPERIMENTAL}

\section{Materials}

The following monomers were applied: butyl acrylate (BA), methyl methacrylate (MMA), methacrylic acid (MAA), n-butyl methacrylate (MBA), methacrylic acid amide (AMAA) (all the materials were produced by Sigma Chemical Co., USA), xylene (analytically pure) produced by POCh Gliwice. The properties of the used surfactants: oxyethylated lauryl alcohol (Rokanol L-10) $\mathrm{C}_{12} \mathrm{H}_{25} \mathrm{O}\left(\mathrm{CH}_{2} \mathrm{CH}_{2} \mathrm{O}\right)_{10} \mathrm{H}$, oxyethylated unsaturated fatty alcohol (Rokanol O-18) $\mathrm{C}_{17} \mathrm{H}_{34} \mathrm{O}\left(\mathrm{CH}_{2} \mathrm{CH}_{2} \mathrm{O}\right)_{18} \mathrm{H}$, oxyethylated nonyl fenol (Rokafenol N-8) $\mathrm{C}_{9} \mathrm{H}_{19} \mathrm{C}_{6} \mathrm{H}_{4}\left(\mathrm{CH}_{2} \mathrm{CH}_{2} \mathrm{O}\right)_{8} \mathrm{H}$, oxyethylated fatty amine (Rokamin SR-8) $\quad \mathrm{C}_{17} \mathrm{H}_{35} \mathrm{~N}\left[\left(\mathrm{CH}_{2} \mathrm{CH}_{2} \mathrm{O}\right)_{4}\right]_{2} \mathrm{H}_{2}$, oxyethylated fatty amine (Rokamin SR-22) $\mathrm{C}_{17} \mathrm{H}_{35} \mathrm{~N}\left[\left(\mathrm{CH}_{2} \mathrm{CH}_{2} \mathrm{O}\right)_{11}\right]_{2} \mathrm{H}_{2}$, sodium salt of the adduct of 
monoesters of succinic acid and oxyethylated nonyl fenol (Sulfosuccinate N-5) $\mathrm{C}_{9} \mathrm{H}_{19} \mathrm{C}_{6} \mathrm{H}_{4} \mathrm{O}\left(\mathrm{CH}_{2} \mathrm{CH}_{2} \mathrm{O}\right)_{5} \mathrm{COCH}_{2} \mathrm{CH}_{2} \mathrm{COOSO}_{3} \mathrm{Na}$, (produced by Rokita Chemical Co. in Brzeg Dolny, Poland).

\section{Preparation of copolymers}

A synthesis of the copolymer used for further studies was carried out by copolymerization or polymerization in xylene. There were obtained: copolymer methyl methacrylate - butyl acrylate - methacrylic acid (MMA/BA/ MAA), copolymer n-butyl methacrylate - methacrylamide (MBA/AMAA), and also polymer MBA of molar composition given in

Table 1. Tret-butyl perbenzoate (Interox TBPB) in the amount of $1,2 \% \mathrm{w} / \mathrm{w}$ with respect to the total monomer weight was applied as an initiator of copolymerization. The reaction was conducted at the temperature of $130-$ $135^{\circ} \mathrm{C}$ for 12 hours. After finishing the reaction, the remaining, not reacted monomers with app. $200 \mathrm{~cm}^{3}$ of xylene were distilled off ${ }^{17}$. The properties of the obtained copolymers and the polymer were determined by gel chromatography and are presented in Table 2.

\section{Preparation of water dispersions of copolymer solutions in xylene}

$100 \mathrm{~cm}^{3}$ of aqueous dispersions of copolymer solutions in xylene contained $20 \mathrm{~cm}^{3}$ of xylene solution of copolymer or polymer and app. 0.5 to $6.0 \% \mathrm{w} / \mathrm{w}$ of the surfactant with respect to the amount of polymer or copolymer. The surfactants were used as aqueous solutions of the concentration of app. $0,2 \% \mathrm{w} / \mathrm{w}$.

A suitable amount of xylene solution of copolymer or polymer and aqueous solution of the surfactant was introduced into a vessel of homogenizer and distilled water was added to obtain $100 \mathrm{~cm}^{3}$. Dispergation was carried out for 20 minutes, using a laboratory homogenizer of the
IKA-ULTRA-TURRAX T-25 type equipped with the IKA-S25N-18G stirrer. The obtained dispersions were poured into the sedimentation cylinders and left for 7 days.

\section{Experimental methods}

The research on the properties of the water dispersions of xylene solutions of acrylic polymer and polymers were made by using the sedimentation methods. The miscibility coefficient $(\beta)$ of the components of the disperse system was calculated basing on the values of Hildebrand's solubility parameters for the individual compounds $\left[\delta_{1}\right.$ and $\delta_{2}$ in $\left(\mathrm{J} / \mathrm{m}^{3}\right)^{0,5 * 10^{3}}$, according to the following equa$\operatorname{tion}^{18-21}$ :

$\lg W_{d}=a \lg \left(c_{s p c} / c_{p o l}\right)+b$

The quantitative and qualitative composition of the tested solutions of polymers was determined by gel chromatography. The tests were made by using the HPLC chromatograph (MERC-HITACHI) equipped with the D2520 GPC integrator.

\section{RESULTS AND DISCUSSION}

Dispergation of the xylene solution of acrylic copolymer in water in the presence of surfactants results in the formation of a disperse system containing particles with their copolymer nuclei. The structure of the surface active film, particularly the presence of copolymer functional groups, determines the basic properties of the tested disperse system, such as long-lasting aggregation and sedimentation stability. The structure is mainly affected by the flocculation and coalescence of micelle particles, occurring inside the volume of the disperse system. It is related to a strongly disintegrated phase of the copolymer solution in water environment that tends to decrease its specific surface. It is achieved by joining the particles into

Table 1. The compositions of the copolymer synthesized with xylene

\begin{tabular}{|c|c|c|c|c|c|c|c|c|}
\hline \multirow[b]{3}{*}{ Copolymer no. } & \multicolumn{4}{|c|}{ Copolymer MMA/BA/MAA } & \multirow{3}{*}{$\begin{array}{l}\text { No. of } \\
\text { polymer } \\
\text { or } \\
\text { copolymer }\end{array}$} & \multirow{2}{*}{\multicolumn{3}{|c|}{$\begin{array}{c}\text { Polymer MBA or } \\
\text { copolymer MBA/AMAA }\end{array}$}} \\
\hline & \multirow[b]{2}{*}{$\begin{array}{l}\text { MMA } \\
\text { [mole] }\end{array}$} & \multirow[b]{2}{*}{$\begin{array}{c}\text { BA } \\
{[\text { mole }]}\end{array}$} & \multirow[b]{2}{*}{$\begin{array}{l}\text { MAA } \\
{[\text { mole] }}\end{array}$} & \multirow[b]{2}{*}{$\begin{array}{c}\text { Copolymer } \\
\text { concentration } \\
\text { in xylene }\left[\mathrm{g} / \mathrm{cm}^{3}\right]\end{array}$} & & & & \\
\hline & & & & & & $\begin{array}{l}\text { MBA } \\
\text { [mole] }\end{array}$ & $\begin{array}{l}\text { AMAA } \\
\text { [mole] }\end{array}$ & $\begin{array}{c}\text { Polymer } \\
\text { or copolymer } \\
\text { concentration in } \\
\text { xylene }\left[\mathrm{g} / \mathrm{cm}^{3}\right]\end{array}$ \\
\hline 1 & 0.75 & 0.2 & 0.05 & 0.264 & 1 & 1.0 & - & 0.262 \\
\hline 2 & 0.55 & 0.4 & 0.05 & 0.274 & 2 & 0.975 & 0.025 & 0.338 \\
\hline 3 & 0.35 & 0.6 & 0.05 & 0.266 & 3 & 0.95 & 0.05 & 0.288 \\
\hline 4 & - & 0.95 & 0.05 & 0.268 & 4 & 0.90 & 0.10 & 0.328 \\
\hline
\end{tabular}

Table 2. The properties of the obtained copolymers and the polymer

\begin{tabular}{|c|c|c|c|c|}
\hline Type of copolymer & $\begin{array}{c}\text { MMA/BA/MAA } \\
1\end{array}$ & $\begin{array}{l}\text { MMA/BA/MAA } \\
2\end{array}$ & $\begin{array}{l}\text { MMA/BA/MAA } \\
3\end{array}$ & $\begin{array}{c}\mathrm{BA} / \mathrm{MAA} \\
4\end{array}$ \\
\hline $\begin{array}{l}\text { Equivalent average } \\
\text { molecular weight }(\mathrm{Mz})^{*} 10^{-3}\end{array}$ & 152.2 & 146.2 & 179.4 & 138.1 \\
\hline $\begin{array}{l}\text { Viscosity average molecular } \\
\text { weight }(\mathrm{Mv})^{\star} 10^{-3}\end{array}$ & 63.7 & 65.3 & 67.0 & 62.1 \\
\hline $\begin{array}{l}\text { Heterogeneity factor } \\
\mathrm{u}=(\mathrm{Mw} / \mathrm{Mn})\end{array}$ & 4.070 & 4.340 & 3.957 & 4.178 \\
\hline $\begin{array}{l}\text { Type of polymer or } \\
\text { copolymer }\end{array}$ & $\begin{array}{c}\text { MBA } \\
1\end{array}$ & $\begin{array}{l}\text { MBA/AMAA } \\
2 \\
\end{array}$ & $\begin{array}{l}\text { MBA/AMAA } \\
3 \\
\end{array}$ & $\begin{array}{c}\text { MBA/AMAA } \\
4\end{array}$ \\
\hline $\begin{array}{l}\text { Equivalent average } \\
\text { molecular weight }(\mathrm{Mz}) * 10^{-3}\end{array}$ & 130.5 & 124.6 & 124.1 & 125.7 \\
\hline $\begin{array}{l}\text { Viscosity average molecular } \\
\text { mass }(\mathrm{Mv}) * 10^{-3}\end{array}$ & 65.7 & 67.0 & 62.2 & 63.4 \\
\hline $\begin{array}{l}\text { Heterogeneity factor } \\
\mathrm{u}=(\mathrm{Mw} / \mathrm{Mn})\end{array}$ & 5.1065 & 5.641 & 5.173 & 5.496 \\
\hline
\end{tabular}


associates producing a homogenous layer of xylene solution of the polymer or copolymer. After a sufficiently long time, sedimentation equilibrium is settled down in the system, which consists in the fact that volumes and compositions of the formed phases practically do not change. Figure 1 presents sedimentation studies carried out in the cylinders.

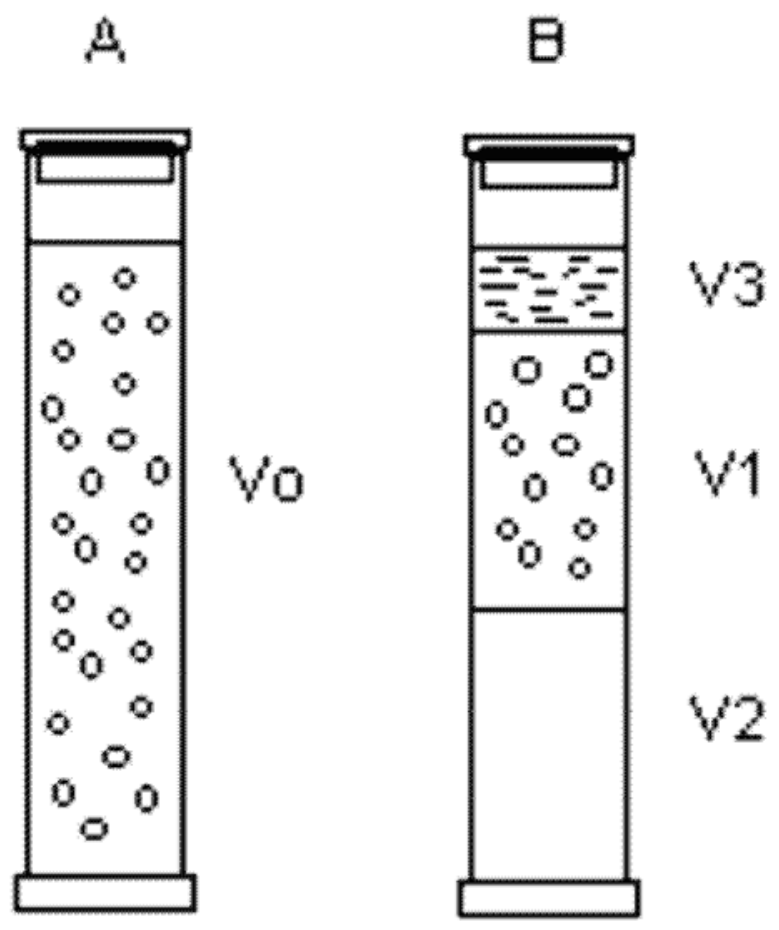

Figure 1. Sedimentation tests of water-based dispersions of xylene solutions of acrylic polymers. Notes: A freshly prepared water-based dispersion, B - water-based dispersion after a seven-day exposure to attain the state of sedimentation equilibrium, $\mathrm{V}_{0}-$ total dispersion volume, $\mathrm{V}_{1}$ - volume of the stable dispersed phase (studied part), $\mathrm{V}_{2}$ - volume of the aqueous phase, $V_{3}$ - volume of the phase of the polymer/copolymer xylene solution

Figure 1 presents water-based disperse in sedimentation cylinders immediately after preparation and after seven days of sedimentation. The possible behaviour of the disperse systems after reaching the sedimentation equilibrium is shown. The appearance of the phase separation with the formation of a layer of the xylene solution of polymer or copolymer, a stable dispersion layer and a water layer were observed. Figure 2 presents a change in the efficiency of dispergation, i.e. a practical change of the copolymer amount in the disperse phase in relation to the exposure time for a few selected concentrations of the surface-active agent.

Basing on the data presented in Fig. 2, one can state that during the seven days of sedimentation the sedimentation equilibrium is actually produced. The sedimentation tests were made for all the disperse systems, the results of which were used to determine the maximum value of the dispergation efficiencies relating to the amount and the type of the used surfactant. Figure 3 presents the values of dispergation efficiency as a function of the amount of a surfactant in the aqueous dispersion of xylene solution after the seven-day sedimentation exposure.

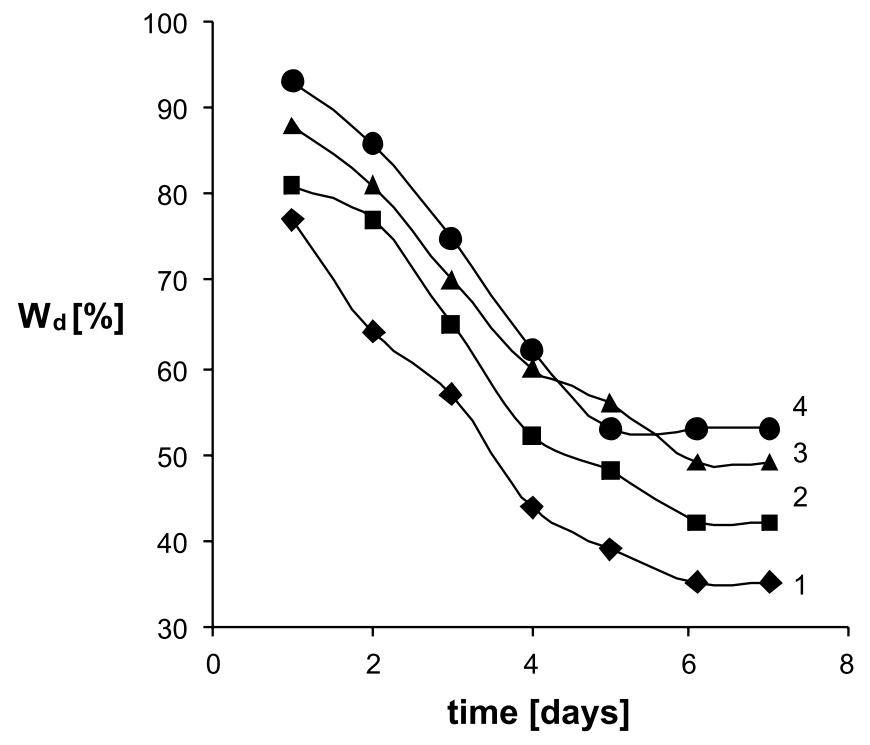

Figure 2. Dispergation efficiency as a function of the sedimentation exposure time for the water-based dispersion of xylene solution of the copolymer MMA/ BA/MAA (1) stabilized with lauryl alcohol (Rokanol L-10). Notes: $1-\mathrm{c}_{\mathrm{spc}} / \mathrm{c}_{\mathrm{pol}}=0.015,2-\mathrm{c}_{\mathrm{spc}} / \mathrm{c}_{\mathrm{pol}}=0.020$, $3-\mathrm{c}_{\mathrm{spd}} / \mathrm{c}_{\mathrm{pol}}=0.035,4-\mathrm{c}_{\mathrm{spc}} / \mathrm{c}_{\mathrm{pol}}=0.050$

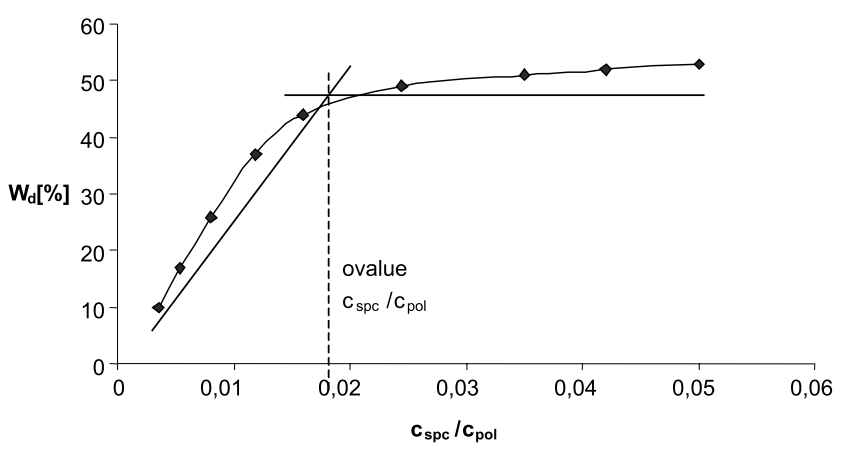

Figure 3. The maximum dispergation efficiency of the water-based disperse system of xylene solution of the copolymer MMA/BA/MAA.(1) as a function of the amount of oxyethylated lauryl alcohol (Rokanol L-10)

Similar dependences to that shown in Fig. 3 were obtained for all the water-based dispersions of xylene solutions of the tested copolymers and polymer: MMA/BA/ MAA, MBA/AMAA and MBA stabilized with applied surfactants. This enabled us to determine a max. value of the dispergation efficiency and, corresponding with it, the optimum concentration of the used surfactant. The study was based on ten trials testing different concentrations of the applied surfactant. Table 3 presents the results of the studies.

The data presented in Table 3 should be considered separately for each type of the copolymer. For the MMA/ BA/MAA copolymer one can note that the optimum values of the maximum dispergation efficiency increase with the increase in fraction of butyl acrylate (BA) in the tested copolymer, whereas the optimum values of the surfactant concentrations decrease slightly. It can be observed that the surfactants with a lower value of cmc correspond to the highest value of max. dispergation efficiency. Considering the water-based dispersions of the MBA/AMAA copolymer, a structure of the copolymer affects slightly both the optimum value of maximum dispergation effi- 
Table 3. The maximum values of dispergation efficiency and optimum amounts of the surfactant in relation to a type of the polymer and copolymers

\begin{tabular}{|c|c|c|c|}
\hline Type of copolymer & Type of surfactant & $\begin{array}{c}\text { Max. } \\
\text { dispergation } \\
\text { efficiency } \\
W_{d}[\%]\end{array}$ & $\begin{array}{c}\text { Optimum } \\
\text { concentration } \\
\mathrm{c}_{\mathrm{spd}} / \mathrm{c}_{\mathrm{pol}}\end{array}$ \\
\hline \multirow{4}{*}{$\begin{array}{c}\text { MMA/BA/MAA (1) } \\
0.75 / 0.2 / 0.05\end{array}$} & Rokanol L10 & 53 & 0.018 \\
\hline & Rokanol O-18 & 55 & 0.012 \\
\hline & Rokamin SR-8 & 55 & 0.005 \\
\hline & Rokamin SR-22 & 61 & 0.009 \\
\hline \multirow{4}{*}{$\begin{array}{l}\text { MMA/BA/MAA (2) } \\
0.55 / 0.40 / 0.05\end{array}$} & Rokanol L-10 & 59 & 0.018 \\
\hline & Rokanol O-18 & 64 & 0.011 \\
\hline & Rokamin SR-8 & 57 & 0.005 \\
\hline & Rokamin SR-22 & 63 & 0.007 \\
\hline \multirow{4}{*}{$\begin{array}{c}\text { MMA/BA/MAA (3) } \\
0.35 / 0.6 / 0.05\end{array}$} & Rokanol L-10 & 64 & 0.016 \\
\hline & Rokanol O-18 & 68 & 0.011 \\
\hline & Rokamin SR-8 & 62 & 0.004 \\
\hline & Rokamin SR-22 & 67 & 0.005 \\
\hline \multirow{4}{*}{$\begin{array}{l}\text { BA/MAA (4) } \\
0.95 / 0.05\end{array}$} & Rokanol L-10 & 78 & 0.016 \\
\hline & Rokanol O-18 & 80 & 0.010 \\
\hline & Rokamin SR-8 & 80 & 0.004 \\
\hline & Rokamin SR-22 & 77 & 0.005 \\
\hline \multirow{4}{*}{ MBA (1) } & Rokafenol N-8 & 61 & 0.007 \\
\hline & Rokamin SR-8 & 60 & 0.001 \\
\hline & Rokamin SR-22 & 57 & 0.001 \\
\hline & $\begin{array}{c}\text { Sulfosuccinate N- } \\
5\end{array}$ & 64 & 0.008 \\
\hline \multirow{4}{*}{$\begin{array}{l}\text { MBA/AMAA (2) } \\
0.975 / 0.025\end{array}$} & Rokafenol N-8 & 60 & 0.008 \\
\hline & Rokamin SR-8 & 62 & 0.009 \\
\hline & Rokamin SR-22 & 63 & 0.008 \\
\hline & $\begin{array}{c}\text { Sulfosuccinate N- } \\
5\end{array}$ & 61 & 0.007 \\
\hline \multirow{4}{*}{$\begin{array}{l}\text { MBA/AMAA (3) } \\
\quad 0.95 / 0.05\end{array}$} & Rokafenol N-8 & 63 & 0.007 \\
\hline & Rokamin SR-8 & 65 & 0.008 \\
\hline & Rokamin SR-22 & 67 & 0.008 \\
\hline & $\begin{array}{c}\text { Sulfosuccinate N- } \\
5\end{array}$ & 60 & 0.008 \\
\hline \multirow{4}{*}{$\begin{array}{l}\text { MBA/AMAA (4) } \\
0.90 / 0.1\end{array}$} & Rokafenol N-8 & & 0.007 \\
\hline & Rokamin SR-8 & 69 & 0.008 \\
\hline & Rokamin SR-22 & 69 & 0.008 \\
\hline & $\begin{array}{c}\text { Sulfosuccinate N- } \\
5\end{array}$ & 62 & 0.006 \\
\hline \multicolumn{4}{|c|}{$\begin{array}{l}\mathrm{W}_{\mathrm{d}} \text { : dispergation efficiency, } \mathrm{C}_{\mathrm{spc}} \text { : surfactant concentration, } \mathrm{C}_{\mathrm{pol}} \text { : } \\
\text { polymer concentration }\end{array}$} \\
\hline
\end{tabular}

ciency and, corresponding to them, the amount of the surfactant. Also, a higher value of max. dispergation efficiency corresponds with the lower value of $\mathrm{cmc}$ of the surfactant. An interesting cognitional issue is to find a relation between the optimum value of the max. dispergation efficiency and the optimum amount of the the surfactant used for the copolymer of a definite segmental structure. For this purpose, the results of the tests are presented in a double logarithm system as the relation $\lg \mathrm{W}_{\mathrm{d}}=\mathrm{f}\left[\lg \left(\mathrm{c}_{\mathrm{spc}} / \mathrm{c}_{\mathrm{pol}}\right)\right]$. Figure 4 presents an exemplary curve for the water-based dispersions of xylene solutions of the MBA/AMAA copolymer (4).

The data presented in Table 3 form a straight line which can be described by the following equation:

$\lg W_{d}=a \lg \left(c_{s p c} / c_{p o l}\right)+b$

where: $\boldsymbol{a}$ is the tangent of the straight line slope, constant $\boldsymbol{b}=\lg \mathrm{W}_{\text {do }}$ when $\left(\mathrm{c}_{\mathrm{spc}} / \mathrm{c}_{\mathrm{pol}}\right)=0$. It can be supposed that constant $\boldsymbol{b}$ corresponds to max. value of dispergation when there are no more surfactant in the water-based dispersion and the stability of the disperse system is provided by the adsorption on the surface of the polymer particle of the oriented dipoles of the water environment. Table 4 presents

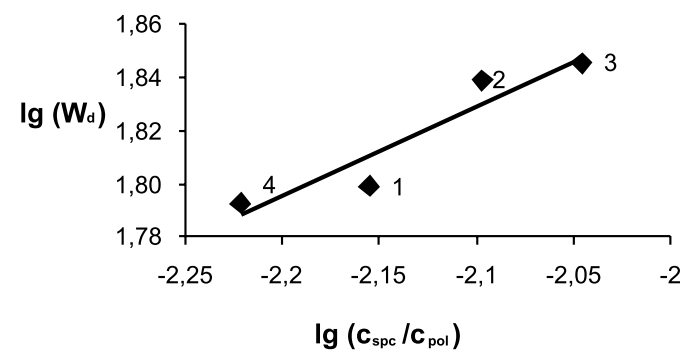

Figure 4. Interrelation between the maximum value of dispergation efficiency $\left(\mathrm{W}_{\mathrm{d}}\right)$ and the optimum value of the surfactant concentration for the water-based xylene solution of copolymer MBA/AMAA (4). Notes: 1-Rokafenol N-8, 2-Rokamin SR-8, 3Rokamin SR-22, 4- Sulfosuccinate N-5

the values of the obtained constants for the water-based disperse systems for both copolymers, taking into consideration their segmental structure.

Table 4. The values of the constants of equation 2 for the tested water-based disperse systems of xylene solutions of polymer and copolymers

\begin{tabular}{|c|c|c|c|c|c|c|}
\hline \multirow{2}{*}{ No. } & \multicolumn{3}{|c|}{$\begin{array}{c}\text { Copolymer MMA/BA/MAA and } \\
\text { BA/MAA }\end{array}$} & $\begin{array}{c}\text { Polymer MBA and copolymer } \\
\text { MBA/AMAA }\end{array}$ \\
\cline { 2 - 7 } & $\mathrm{a}$ & $\mathrm{b}=\lg \left(\mathrm{W}_{\mathrm{do}}\right)$ & $\mathrm{W}_{\mathrm{do}}[\%]$ & $\mathrm{a}$ & $\mathrm{b}=\lg \left(\mathrm{W}_{\mathrm{do}}\right)$ & $\mathrm{W}_{\mathrm{do}}[\%]$ \\
\hline 1 & 0.026 & 1.81 & 59 & 0.05 & 1.77 & 59 \\
\hline 2 & 0.022 & 1.82 & 66 & 0.06 & 1.92 & 83 \\
\hline 3 & 0.024 & 1.86 & 73 & 0.45 & 1.91 & 81 \\
\hline 4 & 0.019 & 1.92 & 83 & 0.39 & 1.90 & 79 \\
\hline
\end{tabular}

Basing on the data in Table 4, it follows that the effect of the copolymer structure on the max. values of dispergation efficiency is clear and obvious. For the MMA/ BA/MAA copolymer, the max. value of the dispergation efficiency increases along with the increase in butyl acrylate fraction in the copolymer structure. However, in the case of the MBA/AMAA copolymer, we can observe at first a slight increase in the max. value of dispergation efficiency and then its decrease when methacrylamide fraction in the copolymer increases. The explanation of the reasons why the sedimentation occurs in this way is worth noticing. It is most probably associated with the segmental structure of the copolymer, which in the case of the MMA/BA/MAA copolymer consists of a constant amount of methacrylic acid, a decreasing fraction of methyl methacrylate and an increasing fraction of butyl acrylate, as shown in Table 1 . In the copolymer macroparticle chain, butyl acrylate forms elastic segments that easily undergo xylene solvation and are more favourable for larger adsorption of the surface-active agent. In turn, the MBA/AMAA copolymer is composed of two monomers, which, as separate substances, form hard and glassy polymers. The obtained copolymer is also hard and, in this case, one should take into consideration only the behaviour of the amide group. The maximum value of dispergation efficiency at first increases with the methacrylamide amount up to max. value of 0,1 mole in the copolymer and then decreases. It is undoubtedly caused by the interaction of a nitrogen atom in the amide group with the groups of the used surfactant, generally with an oxyethylated one. The increase in the concentration of methacrylic acid more than 0,1 mole of AMAA in the copolymer precludes the formation of stable water-based disperse system. In this case, the polymer settles in a form 
of the fine granular deposit. In turn, constant a describes the way in which the max. value of dispergation efficiency changes. If we consider the water-based disperse systems of the MMA/BA/MAA copolymer, we find that it follows in the same way. However, the behaviour of the MBA/ AMAA copolymer is different. The a value increases considerably, which indicates an essential effect on the interaction between the surface of the dispersed phase particles and the particles of the surfactant and the environment. It also indicates that above some limit it is practically impossible to achieve a stable dispersion.

An interesting research issue is to find theoretic justification for the above-described experimental correlations. For this purpose we decided to use the idea of dipole moment and Hildebrand's parameter, especially a miscibility coefficient between the components of the disperse system. Table 5 presents the values of the miscibility coefficients for individual components of the water-based systems, calculated from the Hildebrand's parameter. A dipole moment of the polymer or copolymer was calculated as an additive quantity, basing on molar fractions of the copolymer components. The miscibility coefficient is defined as a square root of the difference between squared Hildebrand's solubility parameters of two components interacting with another one in the disperse system. The miscibility coefficient was calculated using the formula (1) and the data given in monograph ${ }^{22}$.

The data presented in Table 5 show that the calculated value of dipole moment is practically constant and the value of miscibility coefficient decreases with the increase in butyl acrylate fraction in the MMA/BA/MAA copolymer. It means that the copolymer containing a higher fraction of n-butyl acrylate will be better soluble in xylene. This conclusion was confirmed experimentally: the water-based disperse systems containing copolymers with higher amounts of n-butyl acrylate are more stable. Analysing the values of the dipole moments for MBA polymer and the MBA/AMAA copolymer one can notice that these values increase with the increase in the methacrylamide fraction in the copolymer. It means that such a polymer will be more polar and less soluble in xylene. The above observation is confirmed by the calculated values of the miscibility coefficient. It is experimentally proven that water dispersions of highest stability are obtained from MBA/AMAA copolymer (2). However, it is not possible to obtain stable water dispersion from the xylene solution of the MBA/AMAA copolymer containing more than 0.1 mole of AMAA.

\section{CONCLUSION}

Stable disperse systems are produced when dispergation surfactants are adsorbed on particle surfaces of the dispersed phase. Water-based disperse systems of xylene solutions of MMA/BA/MAA and MBA/AMAA copolymers cannot exist individually in the absence of surfactants.

The molecules that are adsorbed on the surfaces of the dispersed phase form protecting layers/coatings. These layers prevent their aggregation and coagulation.

The obtained results show that the stability of a disperse system considerably depends on the structure of the copolymer, which forms the micella kernel of a disperse particle. The MMA/BA/MAA copolymer has monomeric units of butyl acrylate, which makes the copolymer elastic. Segments containing these monomeric units adsorb surfactants much better and form more stable water disperse systems. However, for copolymer MBA/AMAA, the polarity of amide group of methacrylamide limiting the adsorption of surfactants is of significant importance. In this case the stability of disperse systems is lower.

\section{LITERATURE CITED}

1. Grad, P.J., Oldring, P. \& Clarke, J. (1994). The Chemistry of Waterborne Acrylics. P. Oldring \& P. Lam (Eds.), Waterborne and solvent based acrylics and their end user application (pp. 105 - 176). London,UK: SITA Technology Limited.

2. Bouvy, A. \& Opstaele, A. (1995). Polymeric Surfactants and Their Application in Resin Emulsification. D.R. Karsa \& W.D. Davies (Eds.), Waterborne Coatings and Additives (pp. 190 - 201). Cambridge, UK : The Royal Society of Chemistry.

3. Hunter, R.J. (1989). Foundation of Colloid Surface (vols. 1 and 2). Oxford, UK :ClarendonPress.

4. Lyklema, J.(1995). Fundamentals of Interface and Colloid Surface (vol. 1). New York, USA: Academic Press.

5. Candan, F. \& Ottewill, R.H. (1990). Scientific Methods of Polymer Colloids and their Applications. Dordrecht, NL: Kluwer Academic Publishers.

6. Ahualli, S., Delgado, A.V., Miklavcic, S.J. \& White, L.R. (2007). Use of a cell model for the evaluation of the dynamic mobility of spherical silica suspensions. Journal of Colloid And Interface Science. 309, 342 - 349.

7. Husband, J.C. (1998). Adsorption and rheological studies of sodium carboxymethyl cellulose onto kaolin: effect of degree of substitution. Colloids and Surfaces A., Physicochemical and Engineering Aspect. 134, 349 - 358.

8. Ho, C.C. \& Ottewill, R.H. (1998). Investigation of the charge distribution of ellipsoidal particles. Colloids and Surfaces A., Physicochemical and Engineering Aspects. 141, 29 - 35.

Table 5. The calculated mean values of dipole moments and the miscibility coefficients of the polymer or copolymer with xylene

\begin{tabular}{|c|c|c|c|c|c|}
\hline $\begin{array}{c}\text { Components of water-based } \\
\text { dispersions }\end{array}$ & $\begin{array}{l}\text { Dipole moment of } \\
\text { the copolymer }\end{array}$ & $\begin{array}{c}\text { Miscibility } \\
\text { coefficient } \\
\beta^{\star} 10^{3} \\
\left(\mathrm{~J} / \mathrm{m}^{3}\right)^{0,5}\end{array}$ & $\begin{array}{l}\text { Components of water- } \\
\text { based dispersions }\end{array}$ & $\begin{array}{l}\text { Dipole moment of } \\
\text { polymer and } \\
\text { copolymer }\end{array}$ & $\begin{array}{c}\text { Miscibility } \\
\text { coefficient } \\
\beta^{*} 10^{3} \\
\left(\mathrm{~J} / \mathrm{m}^{3}\right)^{0,5}\end{array}$ \\
\hline $\begin{array}{c}\text { MMA/BA/MAA- xylene (1) } \\
0.75 / 0.2 / 0.05\end{array}$ & 0.648 & 5.02 & $\begin{array}{c}\text { MBA- xylene (1) } \\
1,0\end{array}$ & 0.65 & 2.67 \\
\hline $\begin{array}{c}\text { MMA/BA/MAA- xylene (2) } \\
0.55 / 0.4 / 0.05\end{array}$ & 0.648 & 4.80 & $\begin{array}{c}\text { MBA/AMAA- xylene (2) } \\
0.975 / 0.025\end{array}$ & 0.66 & 0.85 \\
\hline $\begin{array}{c}\text { MMA/BA/MAA- xylene (3) } \\
0.35 / 0.6 / 0.05\end{array}$ & 0.648 & 4.52 & $\begin{array}{c}\text { MBA/AMAA- xylene (3) } \\
0.95 / 0.05\end{array}$ & 0.67 & 3.01 \\
\hline $\begin{array}{c}\text { BA/MAA- xylene (4) } \\
0.95 / 0.05\end{array}$ & 0.648 & 3.40 & $\begin{array}{c}\text { MBA/AMAA- xylene (4) } \\
0.90 / 0.1\end{array}$ & 0.69 & 5.49 \\
\hline
\end{tabular}


9. Goodwin, J.W. (2004). Colloids and Interfaces, with Surfactants and Polymers: An Introduction. New York, USA: Wiley.

10. Napper, D.M. (1983). Polymeric Stabilization of Colloidal Dispersions. London, UK: Academic Press.

11. Gurumayum Sharma, S.D., Moreton, D. \& Vincent, B. (2003). Adsorption isotherm and atomic force microscopy studies of the interactions between polymers and surfactants on steel surfaces in hydrocarbon media. Journal of Colloid and Interface Science. 263, 343 - 349.

12. Morisson, I.D. \& Ross, S. (2002). Colloidal Dispersions: Suspensions, Emulsions and Foams. New York, USA: Academic Press.

13. Sonntag, H. \& Strenge, K. (1972). Coagulation and Stability of Disperse Systems, New York, USA: Halsted Press.

14. Pashley, R.M. (2004). Applied Colloid and Surface Chemistry. New York, USA:Wiley.

15. Brostow, W., Pal, S. \& Singh, R.P. (2007). A model of flocculation. Materials Letters. 61, 4381 - 4384.

16. Makarewicz, E. (1997). An effect of non-ionic lipidhydrophilic surfactants on stability of the water emulsions of acrylate-methacrylate resin. Progress in Organic Coatings. 31, $217-222$.

17. Makarewicz, E. \& Zalewska, A. (2005). The analysis of phenomena and factors having an effect on the sedimentation stability and rheology of water-based dispersions of MMA/BA/Maa copolymer in xylene. Progress in Organic Coatings. 54, $43-54$.

18. Izmailova, V.N., Yampolskaya, G.P. (1998). Concentrated emulsions stabilized by macromolecules and the contributions of Hans Sonntag to this scientific field. Colloids and Surfaces A., Physicochemical and Engineering Aspects. 142, $125-134$.

19. Fordedal, H., Schildberg, Y., Sjoblom, J. \& Volle, J.L. (1996). Crude oil emulsions in high electric fields as studied by dielectric spectroscopy. In fluence of interaction between commercial and indigenous surfactants. Colloids and Surfaces A., Physicochemical and Engineering Aspects. 106, 33 - 47.

20. Hotrum, N.E., van Vliet, T., Cohen Stuart, M.A. \& van Aken, G.A. (2002). Monitoring Entering and Spreading of Emulsion Droplets at an Expanding Air/Water Interface: A Novel Technique. Journal of Colloid and Interface Science. 247, $125-131$.

21. Atkins, P.W. (1996). The Elements of Physical Chemistry (second ed.). Oxford, UK: University Press.

22. Van Krevelen, D.W. (1972). Properties of polymers correlations with chemical structure, Amsterdam-London-New York, NL: Elsevier Publishing Co. 